\title{
The Development of Small-micro Technology Enterprises in the Platform of National University Science Park - Take Sanya Yunxin Technology Development Co., Ltd for Example
}

\author{
Yufei Wang 1, 2, a, Mingyu $\mathrm{Li}^{2,3, \mathrm{~b}}$ and Kun Zhang ${ }^{1, \mathrm{c}^{*}}$ \\ College of Ocean Information Engineering, Hainan Tropical Ocean University, Sanya Hainan, 572022, \\ China \\ Sanya Yunxin Technology Development Co., Ltd, Sanya Hainan, 572022, China \\ College of Education, Hainan Tropical Ocean University, Sanya, Hainan, 572022, China \\ a1576949369@qq.com, blimingyu3467@qq.com, * ckunzhang@hainu.edu.cn \\ *The corresponding author
}

Keywords: National University Science and Technology Park; Small-micro enterprises; Science and technology enterprises

\begin{abstract}
This paper analyzes the development factors and existing problems of small micro-tech enterprises. Taking the growth experience of Sanya Yunxin Technology Development Co., Ltd. in Qiongzhou University National University Science Park as an example, this paper analyzes and studies the direction of development of the similar micro-science on National University Science Park Platform, playing a role of demonstration and significance.
\end{abstract}

\section{Introduction}

National University Science and Technology Park is based on the university with a strong scientific research strength, combining the university's comprehensive intellectual resources advantages with other social resources advantages, is a platform and facilitating agency for the transformation of scientific and technological achievements in higher school, high-tech business incubation, training of innovation and entrepreneurship talents, and combined with the platform to provide support and services. First-class national university science and technology park is one of the important symbols of the first-class university, the construction and development of university science and technology park is an important strategic decision of the Party Central Committee and the State Council, during the past 10 years, the Ministry of Science and Technology and the Ministry of Education jointly launched the construction of university science and technology park, and created a road of development of science and technology park with Chinese characteristics. It has made remarkable achievements in the service of economic and social development and the construction of innovation-oriented countries.

\section{The General Development of Small-Micro Technology Enterprises}

The Definition of Small-Micro Technology Enterprises. Small micro-tech enterprises is founded by the technical staff, centering on technical staff, develop, produce and sale high-tech products, turning scientific and technological results to commercialization or providing services of technical development and technical consultation and others, always concerned about market trends, is the substantial economy where depend on self-development with knowledge-intensive. Compared with large and medium-sized enterprises, the size of small-micro enterprises is small, less fixed assets, the amount of mortgage loans are less, and amount of loans are small with short cycle, the risk is relatively high, at the same time, the problems of the weak market competitiveness and asymmetry information of mall-micro enterprises are 
more prominent, whether in economic strength or scientific research capacity, the small-micro enterprises is weak, but it is currently the largest proportion of enterprises in a class. Science and technology enterprises generally have an innovative technology, rather than ordinary enterprises using conventional or stereotypes of technology for production and business activities, which determines if enterprises want to obtain success, they must first obtain a technical breakthrough, therefore, the motivation and pressure of technological innovation for this class of enterprises are higher than these general enterprises.

Development Elements of Small-Micro Technology Enterprise. Enterprise life cycle theory first appeared in 1959, proposed by Mason Haire (Mason Haire), Mason Haire for the first time from the biological perspective combined the "life cycle" with business together. The life cycle of small-micro technology enterprises is also consistent with the common law of enterprise life cycle, that is, a development process from birth to death. The growth stage can be divided into four stages: input period, growth period, maturity stage and recession period. The growth period is a key period for the survival and development of small-micro technology enterprises, and also an important stage of healthy and stable development of enterprises. For the enterprises, growth period is not only the change of amount, more important aspect is the change of essence, and the success factors impacting on healthy growth come from many aspects.

The research on small-micro technology enterprises began in the last century, in recent years, the country put forward the emerging industry strategy where the science and technology as the core, the study of small-micro technology enterprises becomes a hot spot. The success factors of small-micro technology enterprises based on external environment include business environment, government support and market the three key points, the weighing values are $0.444,0.333$ and 0.222 respectively. The weight value of government support is 0.444 , the biggest one in the three influencing factors. This shows that the key of the growth of small-micro technology enterprises to success is government support. This is mainly due to the small-micro technology enterprises in the growth period in addition to the main internal factors, the external policy support is particularly important. Especially in the market economy environment with Chinese characteristics, if small-micro technology enterprises get the government's support, will obtain a very fast growth and success.

The Existing Problems of Development of Science and Technology Enterprises. The competition of world economy and even comprehensive national strength, actually is the competition of scientific and technological strength, the focus of competition is high-tech and its industry. Who hold high-tech advantage will be able to take the initiative in the international competition. As early as the early 1990s, China put forward the strategy of rejuvenating the country through science and education, implementing the strategy of rejuvenating the country through science and education, first of all, we should attach importance to basic education and accelerate the industrialization of high and new technologies. In view of China's reality, to accelerate the industrialization of high-tech has more significant practical significance, but so far the development of this road is still facing many practical problems.

In China, enterprises are not the main body of $\mathrm{R} \& \mathrm{D}$ in the past, enterprise development mainly depends on the extension of production, so that sink into the "high input - high consumption - low efficiency - low efficiency" vicious circle in the long-time. In order to improve the research and development capability of the enterprises, the State Economic and Trade Commission has set up engineering research center in 203 large enterprises. The National Science and Technology Commission has also set up 79 engineering research centers in universities and scientific research institutions aiming at promoting the rapid engineering, industrialization and commercialization of scientific and technological achievements in China. However, from the situation of these two types of centers, there is a lack of support and restraint in the continuity of factors such as talent, funds, projects and information. The operating mechanism is often not perfect and the operation is not smooth. 
Problems in the mode of production and research. In fact, the rise of high-tech industry need to go through the technical concept (1)-principle prototype (2)-product prototype (3)-industry (4)- these three processes. (1) to (2) is the theoretical research and the key technology breakthrough, that is, "learning" process; (2) to (3) is that the engineering and technical researchers according to market demand transfer research results to product, that is, "research" process; (3) to (4) is process that the enterprise will carry out production, sales, to make a profit, that is, "production" process. How to implement the industrialization of scientific and technological achievements according to the above characteristics is an important subject for China's economic development. The state has invested a lot of money and promulgated many preferential policies, but the performance and expectations have been different over the years. The crux of the problem lies the three seriously disjunction in the implementation of basic theoretical research, engineering research and industrial operation, not treating market oriented, and common interests as the driving, resulting in low harvest in spite of huge research funds invested by the country, scientific research results are shelved. With the passage of time, scientific research stepped into the fate cycle of "advanced - backward - out - restudy".

In fact, many countries in the world have treating setting up a university science and technology park as an important way to develop education, revitalize science and technology, and face the world. Because the university science and technology park has become the birthplace of many high-tech enterprises and the base of the industrialization of scientific and technological achievements, it plays increasingly important role of country and regional economic development . In this context, colleges and universities based on their own conditions and advantages to set up science and technology enterprises, form self-building technology platform to speed up the transformation of scientific and technological achievements in schools to promote the development of national high-tech industries and serve the needs of the target of the national economic construction and national strategy, is undoubtedly one of the inevitable choices for the implementation of "science and education" strategy in this stage.

\section{The Advantages of the National University Science Park Platform}

University science park enterprises have become the main force of high-tech industrialization, making great contributions for the national economic development and comprehensive national strength. However, it also faces some serious problems, such as corporate governance, financing, management, intellectual property protection, improper handling of these issues will restrict the growth of start-ups, and even determine the rise and fall of the enterprises. The enterprises are just like the seeds in need of sunshine and soil, start-ups need a good business environment.

The Establishment of University Science Park is Conducive to Turn Scientific and Technological Achievements into Reality of Productivity. So far, 70\% of the major scientific research achievements affecting human life have been born in colleges and universities. In China, it is estimated that during the Ninth Five-Year Plan period, universities undertook more than $1 / 2$ national basic research projects, about one-third of the national 863 high-tech research projects, nearly $1 / 4$ of the national scientific and technological strategic projects. However, due to the imperfect market system, low enterprise innovation capacity, as well as the system and other reasons, so that the phenomenon of the separation of scientific research and production appears. Universities have an advantage in innovation and $\mathrm{R} \& \mathrm{D}$, while in the market phase enterprise are required to operate. To this end, the universities in our country take the initiative, relying on their own technological advantages to set up high-tech enterprises, directly assuming the important task of the commercialization of scientific and technological achievements. Compared with the approaches of the technology trade and licensing, cooperative development and the derivation of high-tech enterprises, the creation of university science and 
technology parks is a more complex and higher-level approach for universities to participate in the development of high-tech industries

Good Entrepreneurial Atmosphere can Remain Young Entrepreneurial Talents. Colleges and universities are the most concentrated areas of high-tech talents, especially, under the influence of "Going Abroad Tide", many high-quality students in Tsinghua University, Peking University as the representative of the domestic first-class institutions treat studying abroad as the first choice after graduation. Although there are many outstanding overseas students return each year, but our country is still facing a serious talents drain. More young people are not attracted by the West's excellent living standards but a more relaxed entrepreneurial environment. The establishment of the science park provides the opportunities and the atmosphere for such entrepreneurship, so that they can see more opportunities to choose to achieve the aspirations of in China, creating a number of outstanding scientific and technological entrepreneurs, they will play great importance in our country's strategy of Rejuvenate China through Science and Education and the development of new economy.

University Science and Technology Park can make the Combination of Production and Research, Training Outstanding Innovative Talents. Cultivating high-quality talents, cultivating students' sense of innovation and ability to solve practical problems has become one of the most urgent tasks of school education under the new situation. University science and technology park hatch through the business, making integration of production and research better, providing a place of practice and exercise for the teachers and students in the university. Teachers practice in the enterprise, taking the lectures in the classroom will be more targeted, talking about their own experience, students can grasp the content better, through business practice, students will also consider to combine their own learning with social needs. And a technology or product research and development need to go through the process of the laboratory to the market repeatedly, university science and technology park as a point of combination, can play a big role.

For the university, the establishment of business incubator, insisting on the market-oriented, treating market demand and social needs as the starting point and the ultimate destination, through the deepening of the education system reform, training and improving the national innovation spirit, innovation sense and innovation capability, to build a good fashion of advocating innovation, encouraging innovation and devoting into innovation in the whole society, to create a new group of talents who understand business, good management and master the modern science and technology knowledge. The function of university science and technology park as this auxiliary education and on-the-job education can not be replaced by other incubators.

\section{Example to Interpret Development of Small-Micro Technology Enterprises in the National University Science and Technology Park Platform}

Qiongzhou University National University Science and Technology Park is the tenth batch, the 115th national university science park, approved by the State Ministry of Education, Ministry of Science and Technology in 2014. Sanya Yunxin Technology Development Co., Ltd. is a hatching enterprise in the Sanya National University Science and Technology Park of Sanya City, which has registered in Sanya municipal industrial and commercial bureau with capital of 2 million, mainly involving in computer, network, digital, information, computer science and technology, network technology. The company respected the entrepreneurial spirit of "innovation, practical, hard work, responsibility", and keep the philosophy of good faith, win-win situation, and create business to create a good business environment. Treating management model, perfect technology, good service, excellent quality as the fundamental of the survival, adhere to use their own scientific and technological innovation services to impress customers and develop the market. At present, the company has two patents of invention, is implementing one of the provincial key scientific and technological projects, at the same time assuming a 
number of IT projects for Sanya enterprises; Companies based on the market of Sanya, facing Hainan Province, the scope of business radiation cover the whole nation, following the market economy, at the same time, walking the way of integration development of production, learning and research, in September 11, 2014, through the first meeting of the Sanya National University Science Park Co., Ltd. Board of Directors, identified as one of the first six admission enterprises to park, developing school-enterprise cooperation, "Take the part-time job practice", "training base", "order - style", "academic alternates", "school and enterprises to build together" and so on, relying on unique advantages of Sanya National University Science Park, so that enterprises and schools achieve the common development, and mutual benefit. The company participated in Sanya City Computer Vision Key Laboratory Construction Projects in 2014 - 2015, to be a policy support project approved by Sanya City Bureau of Science and Technology Bureau in 2016, two projects of the website construction have been completed, solve entrepreneurship, employment for five students. TES

According to the needs of the construction of application college in Hainan Institute of Tropical and Marine, combined with the characteristics of the practice bases, from the subject construction, teaching hardware platform construction and innovative personnel training and other aspects of construction, applying school-enterprise cooperation model, to promote the development of college students in the professional innovation and entrepreneurial capacity, forming the new model of application-oriented personnel training, our company is also improving the economic efficiency of enterprises through the introduction of talent, policy support, innovation and technology production and other aspects.

Yunxin company staff mainly composed of college teachers and students. As a college student, the desire of employees to pursue wealth and their own value is very strong, at the same time, they have excellent quality, with excellent technology, advanced concept and enthusiasm, attaches great importance to their social values, hoping to play their own intelligence in the fierce competition, while the company remove a lot of other concerns for them by relying on the development of university science and technology park, so that they can concentrate on working and make continuous progress in the study.

The company has a good development environment. University Science and Technology Park is adjacent to the University, fully making full use of the university's knowledge, talent and technology advantages, using the human environment, regional characteristics and infrastructure conditions accumulated through decades in the university, with convenient transportation, developed communication, elegant environment and other conditions, providing high quality soft and hard services for the company. At the same time, the establishment of the science and technology park has been supported by the local government and universities, including policy guidance, land concessions, tax relief, financial support, institutional innovation and other supports, reducing the company's risk in such a good business environment, so that the company can develop steadily.

School is the inexhaustible source of technological innovation for university of science and technology park and the company development. Colleges and universities have a wealth of library resources, network resources, a large number of equipment, timely access to the latest technical information. Through the connection with university, companies can learn about the latest ideas, methods and latest scientific and technological achievements of the university, and combine them with market to nurture new ideas, at the same time, feedback to university research institutions to form a new research topic, so the university will provide the company with a steady stream of innovation, the company also provides a realistic direction for the research and development of university.

\section{Summary}

Small-micro Technology enterprises are the most active and innovative groups, has become the important driving force improve the capability of independent innovation and support economic and social development. As a small-micro tech enterprise assigned to the national university science and 
technology park, enterprises rely on the policy support provided by the government, with the help of the development advantage of university science and technology park to solve many urgent problems including capital and environment, to alleviate the small-micro enterprise technical and personnel pressure, at the same time solve the employment pressure for the university. University Science and Technology Park take the scientific and technological development of the line through the cooperation with the enterprise, to promote the achievement of their own function as an incubator, while stimulating the enthusiasm of the university power of science and technology to join in high-tech industrialization, provide experience of cultivating the complex talents for adapting to the new economic development requirements, the relationship between university science park and the park business enterprises is interactive, the success of enterprises is closely related to the healthy development of university science and technology park, through the form of school-enterprise integration, to share resources, continually provide innovative capacity, and ultimately achieve win-win and mutual benefit.

\section{Acknowledgement}

This research was financially supported by the 2015 Innovation and Entrepreneurship Training College National College Projects (No.201511100008).

\section{References}

[1] X.B. Tang: Research on Success Critical Factors in the Growth Stage of Technology-based Small and Micro Enterprises (MS., Central South University, China 2014), p.18-38.

[2] S.S. Li. A Study on the Influencing Factors of the Growth of Science and Technology Small and Medium Enterprises in China (MS., Shandong University, China 2014), p.23.

[3] S.S. Li, Y. M. Zhang: Analysis on the Growth Stage of Small and Medium - sized Technological Enterprises and the Countermeasures. Theory Journal, (2013) No.9, p.50-53.

[4] M. Li: Current Situation and Countermeasures of Enterprise Informationization in Wuhan University. Modern Economic Information, (2013) No.3, p.301-302. 